\title{
La poesia en la prosa de Joan Roís de Corella: delimitació i transmissió del corpus
}

\section{Poetry in Joan Roís de Corella's prose: delimitation and transmission of corpus}

\author{
Josep Lluís MARTos \\ jl.martos@ua.es \\ orcid.org/0000-0002-1379-7536
}

Universitat d'Alacant

\begin{abstract}
Resum: L'obra en prosa de Joan Roís de Corella es caracteritza per incorporar-hi poesies. En aquest sentit, aquest treball té un doble objectiu, que es marca des del seu títol: d'una banda, delimita el corpus, que arriba a catalogar vint-i-un poemes, d'una extensió molt diversa, des d'un sol vers fins a vint-i-vuit; d'una altra banda, estudia la transmissió textual d'aquests poemes, amb especial atenció als trets que caracteritzen els diferents testimonis $\mathrm{i}$ a les particularitats de transmissió dels poemes.
\end{abstract}

Paraules clau: Joan Roís de Corella, poesia, transmissió textual, corpus, codicologia.

\begin{abstract}
The work in prose by Joan Roís de Corella is characterized by the incorporation of poetry. In this sense, this work has a double objective, which is marked by its title. On the one hand, it delimits the corpus, which is able to catalog twenty-one poems, from a very diverse extent, from one vers up to twenty-eight. On the other hand, it studies the textual transmission of these poems, paying special attention to the features that characterize the different testimonies and to the particularities of transmission of poems.
\end{abstract}

Keywords: Joan Roís de Corella, poetry, textual transmission, corpus, codicology.

\footnotetext{
* Aquest treball s'emmarca en el projecte FFI2017-86313-P (AEI/FEDER), concedit pel Ministerio de Economía, Industria y Competitividad, del qual sóc investigador principal.
} 
Josep Lluís Martos. La poesia en la prosa de Joan Roís de Corella: delimitació i transmissió del corpus

En la seua introducció a l'edició crítica de les obres de Joan Roís de Corella, Ramon Miquel i Planas ni tan sols referencia tots els casos en què apareixen versos en la prosa d'aquest autor, sinó que es limita a les dues poesies de la Istòria de Josef, a la del Triümpho de les dones i a la darrera de les $\operatorname{tres}^{1}$ que conté el Debatamb el príncep de Viana, si bé n'esmenta la segona, però en un altre context: a propòsit de la transmissió textual del poema independent d'intercanvi amb aquest mateix personatge (1913: LV-LVI, LX, LXII i LXXXVI-LXXXVII). Tot i que sense individualitzar les cinc composicions del Leànder y Hero, Martí de Riquer (1964: 254-320) sí que es refereix a les setze poesies de dos versos o més inserides en les obres en prosa corellanes. Tant l'un com l'altre s'apropen a aquests poemes o, si més no, en fan esment, quan revisen el contingut de les obres en prosa en qüestió, a la qual cosa afigen sovint una valoració qualitativa dels versos, però, en tot cas amb referències espigolades al llarg dels seus estudis generals.

Jordi Carbonell analitza aquesta tècnica corellana amb una visió de conjunt, tot i que generalitza excessivament, sense que les seues conclusions afecten a tot el corpus de poemes en la prosa, ${ }^{2}$ mentre que Lola Badia és la primera a focalitzar i interpretar la funció del recurs en una obra concreta: La istòria de Leànder y Hero. ${ }^{3}$ Seguint aquesta metodologia, durant les dues darreres dècades he analitzat la poesia en obres concretes en prosa de Roís de Corella i vaig començar a fer-ho amb les composicions del Leànder y Hero i de Lo Johí de Paris, ja que totes dues formaven part del corpus de les proses mitològiques, que vaig editar críticament. ${ }^{4}$ He desenvolupat, així mateix, un treball sobre l'escondit incorporat com a primera composició en vers de la Tragèdia de Caldesa (Martos 2009)

1 D'autoria corellana, perquè n’hi ha una quarta, que apareix en segon lloc, del príncep de Viana.

2 «Aquesta nova manera de fer la narrativa corelliana es caracteritza fonamentalment, en el terreny formal, per l'aplicació a la prosa de les tècniques d'expressió pròpies fins aleshores de la poesia. I no pas de la poesia banal i arcaica dels poetes de certamen, sinó de la poesia personalíssima, nova de trinca, vital, moderna que ja hem vist que Roís de Corella escriví. Això portarà a la inserció freqüent de fragments en vers: la proximitat entre la tònica literària dels fragments en prosa $i$ la dels fragments en vers és tan gran que aquestes insercions no trenquen el ritme de l'obra ni n'interrompen el clima. En realitat, sovint l'estil directe correspon al vers: això es troba dins la línia general estilística de l'autor, que atribueix als mots concrets una importància especial» (Carbonell 1973: 29).

3 «Justament ha fet notar Riquer la singularitat dels versos estramps que corella intercala en aquesta «poesia»; a banda de la seva qualitat i de la fama de què van gaudir alguns, cal observar que apareixen situats en els moments clau de la història: quan Leandre i Hero prenen consciència per separat del seu enamorament (96-104 i 151-153), quan Leandre es llança al mar en tempesta que el farà morir i quan mor (361-368 i 422-255), i finalment quan la noia dicta l'epitafi de tots dos just abans de llevar-se la vida. Es tracta de moments sentimentals perfectament homologables amb els de la tradició trobadoresca que s'han incorporat a la narració com a peces decoratives, dignes de figurar inscrites al peu d'una versió plàstica del relat» (Badia 1988: 173-174).

4 Per als poemes incorporats a aquesta prosa, vegeu la meua edició crítica (Martos 2016a: 56-57, 60, 72, 75 i 93) i, per a la seua anàlisi concreta, remet a l'anotació de la primera fixació textual que vaig fer d'aquesta obra mitològica (Martos 2001a: 154, 156, 162, 164 i 173) i al seu estudi literari (Martos 2001b: 227-263). Per al poema de Lo jobi de Paris, vegeu-ne la meua edició crítica anotada (Martos 2001a: 304) i l'estudi corresponent (Martos 2001b: 283-284).

SCRIPTA, Revista internacional de literatura i cultura medieval i moderna, núm. 14/desembre 2019/pp. 243- 260 ISSN: 2340-4841· doi:10.7203/SCRIPTA.14.16368 
o sobre la relació interpretativa entre aquesta obra i la Lletra consolatòria (Martos 2005a), ${ }^{5}$ una breu prosa profana que es tanca amb la primera cobla del poema Desengany, per acabar de crear un univers de referències conceptuals i claus interpretatives internes. Els apropaments parcials són les dades de base per a poder generar unes conclusions que afecten, amb caràcter global, al mecanisme d'incorporació de la poesia en la prosa de Joan Roís de Corella i així ho vaig fer ${ }^{6}$ en referències a aquest mecanisme en treballs sobre les proses mitològiques (Martos 2001b: 290-291) o sobre la Tragèdia de Caldesa (Martos 2010: 41).

Poc s'ha dit, per tant, de la presència de la poesia en la prosa de Joan Roís de Corella i, quan s'ha fet, sovint ha estat de manera limitada, bé per la brevetat dels apunts, bé perquè es referia a un text concret $-\mathrm{i}$ sempre quant a la producció profana-, ${ }^{7}$ amb manca d'una visió general del fenomen en l'obra corellana o, quan sí que la tenia, amb conclusions que sols explicaven una part dels casos. ${ }^{8}$ Poc s'ha dit, certament, i de manera molt aillada o dispersa, raó per la qual hem de bussejar en una bibliografia que tenia uns objectius més amplis i que incorporava referències breus sobre el tema, que, en qualsevol cas i se'ns dubte, són la base sobre la qual construir una anàlisi de conjunt quant a la praxi corellana d'aquest mecanisme. ${ }^{9}$ Els resultats d'aquesta investigació ${ }^{10}$ m'han

5 De la qual vaig fer la primera i única edició crítica fins ara (Martos 2005b). Abans, l'havia editat Carbonell (1973: 94-96) en una versió actualitzada.

6 Ho vaig intentar, en realitat, però vaig extrapolar conclusions a la resta dels casos de poesia incorporada a la prosa, sense tenir-ne una anàlisi individual de tots i cadascun dels casos en què Corella recorre a aquesta estratègia.

7 Efectivament, poc s'ha dit de la poesia en la prosa de Corella, però res que afectés de manera directa a la seua producció religiosa, més enllà de les breus notes de Miquel i Planas (1913: LV-LVI, LX) o de Riquer (1964: 268, 285, 288). Hem de delimitar, però, què entenem com a obra religiosa, sensu stricto, perquè la inclusió del vers en la prosa obri una doble perspectiva. Tan sols dos d'aquestes vuit obres que incorporen vers són proses religioses, una bíblica i l’altra hagiogràfica, tot i que de models narratius molt semblants: el Josefi la Magdalena. Una obra profana, com és el Triümpho de les dones, es tanca, tanmateix, amb un poema de caire religiós. Aquest corpus d'estudi estaria format, d'aquesta manera, per quatre poemes incorporats a tres obres en prosa, dues de les quals són religioses, mentre que sols un dels poemes ho és en sentit estricte, precisament el que clou una prosa profana, mentre que altres dos, tot i provenir d'una font bíblica, dialoguen amb altres fonts i amb altres obres corellanes, en les quals prima l'expressió lírica. Sobre aquest corpus religiós he desenvolupat recentment una ponència en el Simposi Internacional Literatura i Espiritualitat en els textos valencians del segle XV, que va tenir lloc a València, en la Universitat Catòlica de València, els dies 17 i 18 de novembre de 2019.

8 D’això últim, fonamentalment, en sóc responsable (Martos 2001b: 290-291; Martos 2010: 41), tot i que sí que les conclusions són vàlides per a una part important d'aquests poemes incorporats a la prosa. En el cas de Carbonell (1973: 29), la qüestió és que generalitza massa en assimilar totes aquestes composicions sota una mateixa «tònica literària», que no sabem ben bé què significa i perquè conclou, en negatiu, el que no provoca la incorporació dels poemes - «no trenquen el ritme de l'obra ni n’interrompen el clima»-, però no explica per què recorre Corella a aquesta tècnica.

9 Les primeres conclusions de la qual he presentat com a comunicació en el XVIIIè Congrès Internacional de l'Associació Hispànica de Literatura Medieval (Barcelona, 2-6 de setembre de 2019) i que es publicarà com a article en revista científic.

10 Als quals, a hores d'ara, estic donant forma com a introducció crítica al corpus dels poemes incorporats a les obres en prosa de Joan Roís de Corella. 
Josep Lluís Martos. La poesia en la prosa de Joan Roís de Corella: delimitació i transmissió del corpus

permés concloure que les funcions de la poesia en la prosa corellana van més enllà del clímax líric, pròpiament dit, com jo mateix havia generalitzat, tot i que la bellesa dels versos en qüestió, en la qual ha insistit tant Martí de Riquer, sempre serà una carrega de liricitat important, a la qual, no obstant això, s'hi afigen altres funcions $i$ altres trets que caracteritzen els textos en vers $i$ en prosa, que, en qualsevol cas, s'han d'interpretar en el conjunt de la producció d'aquest autor.

Arribats en aquest punt, d'aquest estat de la qüestió es deriva que no comptem, a hores d'ara, amb un corpus establert dels versos incorporats a la prosa de Corella. La delimitació d'aquest corpus és, per tant, prèvia a qualsevol acció filològica posterior sobre aquest mecanisme, de la mateixa manera que ho és, en la fase de la recensio, el estudi de la transmissió textual d'aquestes composicions per a la fixació dels textos i, en alguns casos, també per a la interpretació. És per això que l'establiment del corpus i l'estudi de la seua transmissió textual són l'objecte central d'aquest treball.

\section{La delimitació del corpus.}

No comptem, fins ara, amb cap estudi monogràfic dedicat a aquesta estratègia literària aplicada a la literatura catalana medieval, però sí alguns en aquesta línea pel que fa a la literatura castellana o a la romànica, centrats, tanmateix, en els límits entre la narrativa i la lírica. El de Carlos Alvar (2019) n'és el més recent, però també caldria destacar, entre d'altres, els estudis pioners d'Alan Deyermond (1975), de Pedro Cátedra (1993) i de Meritxell Simó (1999), amb una interessant perspectiva metodològica i teòrica sobre les fronteres entre ambdós gèneres que, pel seu abast, encara els manté com a referents bibliogràfics essencials. No obstant això, ni les obres tractades, ni els límits d'estudi són identificables amb l'objectiu d'aquesta investigació, perquè el criteri de classificació d'aquest corpus poètic de Roís de Corella no rau en una dicotomia de gèneres -lírica i narrativa-, sinó en una altra, de formal: el vers i la prosa. La versificació serà, per tant, un criteri per a identificar i delimitar el corpus de poemes incorporats a la prosa de Joan Roís de Corella.

No faig sinonímia entre versificació i estrofisme, perquè ha estat un error de mètode, un parany en què ha caigut, fins i tot, Martí de Riquer (1964: 263-313), en destacar-que no catalogar-aquestes poesies quan parlava de les composicions en prosa que les incorporaven. Els testimonis de les obres en qüestió tendeixen a distribuir cada vers en una ratlla diferent de la caixa d'escriptura, en cobles que van des dels 2 fins als 14 versos, a excepció d'uns casos puntuals als quals em referiré després. Són, per tant, fàcils de reconéixer a simple vista en les fonts materials, per aquest tret i per uns altres indicadors formals, com ara els calderons o la marca de cesura.

Ara bé, aquesta tècnica de catalogació, basada en la identitat estròfica i la seua presentació formal en els testimonis, es construeix sobre un dels prejudicis que ha patit durant els últims dos segles la poesia de cançoner, com destaca Keith Whinnom: «cierta falta de respeto por la lírica menor», pues «el hecho de que los poetas cortesanos trabajan por preferencia en los géneros menores también parece haber contribuido a estorbar el justo aprecio de lo que se puede conseguir en el breve 
Josep Lluís Martos. La poesia en la prosa de Joan Roís de Corella: delimitació i transmissió del corpus

espacio de una canción, una esparsa, una letra o un mote» (1981: 85). Entre aqueixa poesia mínima, hi ha poemes d'un sol vers, als quals, no sols en aquest cas, la tradició crítica catalana no ha parat atenció, com ara les letras o els motes de la literatura castellana, que tant van triomfar en la València pre-renaixentista.

Roís de Corella no genera poemes independents d'un vers o, almenys, no ens n’ha quedat testimoni, potser per la poca entitat d'aquests possibles textos, no incorporats a col·leccions en què la seua poesia es transmet, fonamentalment, com a remat de quaderns i de còdexs en els quals prima la prosa (Martos 2013a). Tanmateix, en la seua obra, sí que hi ha mostres d'aquest tipus de poesia breu i conceptual incorporada a la prosa, si més no en Lo jobi de Paris, ${ }^{11}$ que dona cabuda no sols a un poema de sis versos, amb la sentència del judici, ${ }^{12}$ sinó també a cinc composicions d'un únic vers, a manera d'un gènere poètic com les ben conegudes letras de la tradició castellana.

Si per al reconeixement dels poemes de dos o més versos, la seua distribució formal n'era el principal criteri, en les poesies d'un vers s'ha de recórrer al recompte sil·làbic i als accents i, amb ells, a la presència d'hemistiquis. D'aquesta manera, reconeixem en Lo Johi de Paris cinc sentències a línia tirada en la caixa d'escriptura que són, pròpiament, poemes, tot i que tots ells exclusivament d'un vers. D’aquests, un és octosíl·lab, mentre que els altres quatre són decasíl·labs, tots amb accent en la quarta, la qual cosa dona lloc a un primer hemistiqui regular i accents en la sisena i/o huitena síllaba del segon, com és preceptiu i com caracteritza la producció poètica corellana. Un dels decasíllabs, en realitat, computa un segons hemistiqui de set peus: «Venç gran amor paraules, erbes hi pedres». I l'hauríem de considerar, per tant, un vers hipermètric, més enllà que no n'hi haja d'altres per a comparar-lo en la composició pròpiament dita, però sí en el context en prosa, ja que els tres decasíl·labs restants són, com aquest, els poemes epigramàtics que s’incorporen brodats als mantells de les deesses Juno, Pal·las i Venus, en el darrer dels quals, en realitat, hi ha dues cintes o bandes amb aquest tipus de poesia i aquesta n'és la darrera. ${ }^{13}$

La pèrdua de la rima, en ser sols un vers, no és un problema afegit per a la seua consideració com a poema, perquè, de totes les composicions corellanes en vers incorporades a la prosa, sols quatre són rimades -les tres del Debat amb el príncep de Viana i la que clou la Magdalena-, mentre que

11 Tot i que la rúbrica atribueix la secció del mite a Joan Escriva, la qual cosa, com ja vaig explicar i justificar en el seu dia (Martos 2001a i 2001b), és un joc literari, semblant al que trobem en el Parlament en casa de Berenguer Mercader, que no implica, fins i tot, que hagués pogut existir alguna performance en aquest sentit o remetre a algun episodi real -però tampoc la justifica-, la darrera redacció del qual és, indubtablement, corellana.

12 Com hem destacat Riquer (1964: 311-312) i jo mateix (Martos 2001b: 283-284, 290-291).

13 A la manera, per cert, de la que Nicolás Núñez descriu per al seu Leriano: «En la continuación de Cárcel de Amor, Leriano -ya convertido en espectro- aparece al autor vestido de un sayo de terciopelo negro con «una cortadura de raso del mesmo color», y bordada en la prenda una letra que reza: «En la firmeza se muestra / mi mal y la culpa vuestra»»» (Whinnom 1981: 53). No hem d'oblidar que aquest és un poeta valencià, que presenta uns altres punts de contacte amb l'obra de Roís de Corella, sobre les quals estic treballant a hores d'ara i que podrien ser mostra de la pervivència d'aquesta, sobre la qual s'ha conclòs, ja erigit com a tòpic, que l'arribada del castellà a la poesia culta i el consegüent desplaçament del català va generar l'oblit de la seua producció. 
Josep Lluís Martos. La poesia en la prosa de Joan Roís de Corella: delimitació i transmissió del corpus

la resta es construeix amb versos estramps. Com a poemes de vers únic, és lògic que no estem al davant de poesia rimada i, fins a cert punt, tampoc d'estramps, perquè aquest concepte parteix del contrast amb altres versos del poema. Ara bé, el que sí que se'ns hi aporta són paraules en posició de rima, que podem comparar amb els usos corellans.

«Sia donat a la més bella»

«Dins onestat tots mos desigs se tanquen»

«Venç gran amor paraules, erbes hi pedres»

\author{
«Casta serà la vostra no poch bella» (A Caldesa, v. 9) \\ «tart s'esdevé que pels altres la tanque» (Desengany, v. 4) \\ «si ls obre may, la mort soplich los tanque» (Plant d'amor, v. 2) \\ «del primer crim, puix dins la vostra tanqua» (Vida, v. 7)
«lo nostre cor fan molt pus dur que pedra» (Imperfecció humana, v. 2) «hon sereu tret del viu en bella pedra» (Imperfecció bumana, v. 10) «Mudarà $\cdot 1$ gest la mia forma·n pedra» (La Sepultura, v. 26) «vés circumcir ab un coltell de pedra» (Vida, v. 75) «del que Vós, fill, pendreu dins en la pedra» (Oració, v. 34) «en claredat totes les altres pedres» (Sentència-Lo jobi de Paris, v. 5)

Així, Corella utilitza el mot-rima del poema «Sia donat a la més bella» en el vers 9 del seu maldit, en una composició rimada, mentre que el de «Dins onestat tots mos desigs se tanquen» s'utilitza, amb variants morfològiques del verb, en el v. 4 del Desengany i en el v. 7 de la Vida -tots dos poemes en versos estramps-, així com en el v. 2 del Plant d'amor, que, en aquest cas, és rimat. I és que Corella usa, sovint, uns mateixos mots a final de vers tant per a fer rima, com per a construir versos estramps.

Si la combinació de nasal i oclusiva és pròpia dels mots corellans amb rima de fènix (tanqua/tanque/ tanquen), encara són més característics aquells que combinen les consonants oclusives amb líquides, com és el cas de pedra/pedres, que trobem en el poema «Venç gran amor paraules, erbes hi pedres», amb un mot en posició de rima que Corella fa servir en la seua poesia en cinc ocasions més en singular i en una altra, com ací, en plural. En els vv. 2 i 10 d'Imperfecció bumana, la repetició té a veure amb la represa de la rima del primer quartet en la tornada, una rima, que, així mateix, depén de la marcada per Bernat Fenollar en la pregunta a la qual respon Corella amb aquest poema; els altres tres casos de pedra com a mot en posició de rima són, precisament i com correspon als seues trets fònics, uns versos estramps de la Sepultura (v. 26), de la Vida (v. 75) i de l'Oració (v. 34). Aquesta recurrència al mot fènix en qüestió és encara més simptomàtica perquè s'usa també en plural en una altra ocasió i és, precisament, en el vers 5 d'un altre poema incorporat a la prosa de Lo johí de Paris, el que correspon a la Sentència i l'únic de més d'un vers d'aquesta peça, també construït amb estramps: «ni axí venç lo relluent carvoncle / en claredat totes les altres pedres» (vv. 4-5). ${ }^{14}$ Aquest paral·lelisme amb una altra poesia incorporada en aquesta mateixa prosa; la recurrència a

14 He incorporat en la seqüència el vers anterior pel paral·lelisme estructural i lèxic que presenta amb aquest poema brodat en el mantell de Venus, perquè reforça la seua la delimitació com a poema d'un sol vers, tot i ser l'únic hipermètric. Tractaré i resoldré la qüestió ecdòtica en un altre context, en el qual editaré els textos i estudiaré la tipologia de les insercions poètiques. 
Josep Lluís Martos. La poesia en la prosa de Joan Roís de Corella: delimitació i transmissió del corpus

un dels mots més sovintejats per Corella en posició de rima; el fet que es tracte d'un text brodat en una peça de vestir que en contenia, alhora, un altre de semblants característiques, però clarament decasil-làbic; i que s'escriga en una banda de tela, fet que remet a un gènere poètic breu que hi feia, normalment, aquesta funció en obres d'art plàstica; tot plegat justifica que aquesta composició de vers únic hipermètric forma part del corpus poètic de la poesia en la prosa de Joan Roís de Corella.

De l'anàlisi de la vintena d'obres de creació en prosa de Joan Roís de Corella, comproven que se n'incorpora poesia en vuit: en el Debat amb el princep de Viana, en el Triümpho de les dones, en la Lletra consolatòria, en la Tragèdia de Caldesa, en el Leàndery Hero, en Lo jobi de Paris, en el Josefi en la Magdalena. No incorpore a aquesta nòmina La Sepultura de Francí Aguilar, una obra farcida d'exemples semblants als poemes d'un vers de Lo johí de Paris, amb què comparteix el recurs a l'ècfrasi, perquè tots els textos són llatins i també citacions textuals bíbliques, ${ }^{15}$ però no, stricto sensu, creacions corellanes. ${ }^{16}$ I ho faig així malgrat un cas semblant, que incorpora el Cancionero general: el del mote «Transeat a me calix iste» (González Cuenca 2004, II: 634, no 573/1), ${ }^{17}$ també en llatí i reproduint un passatge bíblic, de l'Evangeli de Mateu (Mt 26,39), amb les paraules de Crist en l'hort (Whinnom 1981: 59).

Aquestes vuit obres en prosa recullen vint-i-una composicions en vers, que conformen i delimiten, en definitiva, el corpus de poesia catalana incorporada a la prosa de Joan Roís de Corella:

\section{Debat amb el princep de Viana}

Triümpho de les dones

Lletra consolatòria

Tragèdia de Caldesa

Leànder y Hero
«Beda sou vós, senyor, quant vos contemple»

«D'un bell joyel, senyor, tinch inventiva»

«Senyor del món, qui passau en saber»

«Mare de aquell qui de la creu en l'arbre»

«Los qui amau, preneu aquesta cendra»

«Mourà's corrent la tremuntana ferma» «Clarament veig que·n la mundana orla»

«Tan gran dolor lo meu cor trist esquinça» «Del món no·m dolch, que ma vida vull perdre» «Lo foch que veig encés alt, en la torre» «Cuyta, cos mort, que l'amor que $t$ fa perdre» «Amor cruel, qui $\cdot 1$ ha units en vida»

15 Com ha localitzat Josep Albiñana (1984-1985, II: 562-568, notes 17, 24, 29, 32, 35, 39, 45, 47, 48, 51, 56, 58).

16 No vol dir això que no dedicaré un treball a aquesta obra en prosa i a estudiar la recurrència a aquest mecanisme o un de semblant - perquè cal delimitar-lo en aquest cas- en trufar-la de textos bíblics de la Vulgata llatina.

17 Amb glossa de Soria (González Cuenca 2004, II: 635, nº 573/2).

SCRIPTA, Revista internacional de literatura i cultura medieval i moderna, núm. 14/desembre 2019/pp. 243- 260 
Josep Lluís Martos. La poesia en la prosa de Joan Roís de Corella: delimitació i transmissió del corpus

Lo jobi de Paris

«Sia donat a la més bella»

«Obriu los ulls als dans que seguir poden»

«Dins onestat tots mos desigs se tanquen».

«Lo fruyt d'amor ab gran treball se troba»

«Venç gran amor paraules, erbes hi pedres»

«Preniu lo pom, mare del gran Cupido»

Josef «Morta de part, davall la pedra marbre»

«Mort per amor, dins lo negre sepulcre»

Magdalena 《Fflor d'onestat, senyora devota»

\section{La transmissió textual.}

Les vuit obres en prosa amb poesia es conserven en tres testimonis manuscrits $i$ en un imprés, tot i que amb una distribució irregular: el Cançoner de Mayans (U) (Biblioteca Universitària de València, ms. 728), ${ }^{18}$ el Jardinet d'orats $\left(X^{\prime}\right)^{19}$ (Biblioteca Universitària de Barcelona, ms. 151), el Còdex de Cambridge $\left(X^{2}\right)^{20}$ (Trinity College, R.14.17) i un imprés, sine notis, però valencià i de $c .1500-1502,{ }^{21}$ que recull exclusivament el Josef $(a)^{22}$ (Biblioteca Universitària de València, CF/4-19). ${ }^{23}$

El Cançoner de Maians i el Còdex de Cambridge són reculls monogràfics de l'obra de Joan Roís de Corella, ${ }^{24}$ productes, per tant, que s'interessen de manera directa i particular en la recopilació i

18 Per a la descripció d'aquest cançoner, vegeu Martos 1999a, 2001c i 2005c.

19 Per a la descripció d'aquest cançoner, vegeu Torró 1992 i, per a la presència corellana, Martos 2005c.

20 Per a la descripció d'aquest cançoner, vegeu Martos 1999b i 2005c; per a la seua datació, c. 1502-1504, vegeu Martos 2008a. Pere Bohigas (1985: 37-42) va ser el primer a donar notícia d'aquest còdex en l'àmbit català, en un article de 1927 que se centra, principalment, en la seua descripció.

21 Se n'ha debatut molt l'impressor responsable en els diferents repertoris: Jofré, Llop de la Roca, o Alfons d'Orta o Jorge Costilla. No sembla que estiga resolta la qüestió, per tant.

22 Per a la descripció material d'aquest imprés, vegeu els següents repertoris: Serrano y Morales 1898-1899: 229; Haebler 1903-1917: n 588; Aguiló i Fuster 1923: nº 39; Vindel 1946: n 91; Norton 1978: no 1218; Romero Lucas 2005 : no 83; Martín Abad 2001: no 1334; GW M39161; ISTC id00909470. S’incorpora al conegut volum del Natzaré, per a l'arribada del qual a la Biblioteca Universitària de València remet a Martos 2016b: 246.

23 Les referències sinòptiques que aporte entre parèntesis són, per als manuscrits, les que va establir Jaume Massó i Torrents (1913-1914 i 1932). L'imprés no compta amb una referència d'aquest tipus, en no haver-se considerat un imprés poètic, i podem identificar, per tant, amb una a minúscula, pròpia dels impresos en la tradició catalana i que no ha de traspassar els límits de referència d'aquest treball, perquè entraria en conflicte amb l’imprés que Massó identifica d'aquesta manera, que és l'incunable de les Trobes de 1474.

24 Amb els matisos que això pot tenir, no sols per addicions de copistes o posseïdors posteriors (Ferrando 1981: 391), sinó perquè el Cançoner de Mayans incorpora poesia corellana d'intercanvi i un darrer poema de Fenollar (Parramon 1989; Martos 2012a, 2012b i 2013b), que tanca el còdex, a manera de remat, com ocorre amb la poesia que completen

SCRIPTA, Revista internacional de literatura i cultura medieval i moderna, núm. 14/desembre 2019/pp. 243- 260 
Josep Lluís Martos. La poesia en la prosa de Joan Roís de Corella: delimitació i transmissió del corpus

conservació de la seua literatura, enfront del caràcter antològic del Jardinet d'orats, en el qual, en qualsevol cas, la seua producció té una important presència. ${ }^{25}$ L'abast del Cançoner de Mayans, molt més ambiciós i exhaustiu que el Còdex de Cambridge, justifica que s'hi copien set de les vuit proses en qüestió i que siga, fins i tot, testimoni únic per a dues d'aquestes -el Debat i la Magdalena-, de la mateixa manera que ho és el Còdex de Cambridge per a la Lletra consolatòria (Martos 2005b). De les cinc obres pluritestimonials, totes en el Cançoner de Mayans, se'n recullen quatre també en el Jardinet d'orats -Tragèdia de Caldesa, Leànder y Hero, Lo jobi de Paris i Josef-, mentre que el segon testimoni del Triümpho de les dones és el Còdex de Cambridge. Sols una d'aquestes, la història bíblica del Josef, presenta tres testimonis i el tercer és un imprés valencià incunable o post-incunable, una peculiaritat que no sols contrasta amb la resta de la poesia en la prosa, sinó amb la transmissió textual de bona part de l'obra de creació de Roís de Corella i, en particular, de la profana, de l'arribada de la qual a la impremta no tenim pràcticament notícia, ${ }^{26}$ ni se n’ha conservat cap exemplar.

En els diferents testimonis, els poemes de dos o més versos presenten trets que, d'una manera o d'una altra, faciliten la seua delimitació i el seu reconeixement en una obra en prosa i que, en darrera instància, afecten a la seua transmissió textual. El seu estudi contribueix, per tant, a l'anàlisi de la recensio i, així, en darrera instància, a l'estudi ecdòtic d'aquestes composicions.

En el Cançoner de Mayans, totes aquestes poesies van precedides d'un calderó roig, fet amb un pigment de cera, ${ }^{27}$ de la mateixa grandària i disseny que el de les rúbriques dels epígrafs d'una obra en prosa. ${ }^{28}$ Aquest reconeixement formal de l'entitat del poema dins el text en prosa, introduint un calderó en el primer vers, malgrat no comptar amb rúbrica, és sistemàtic en tots els poemes d'aquest cançoner, com ho és la seua distribució dels versos per línia d'escriptura, de manera que se n'acurta la caixa. Tots dos aspectes, així com la marca de cesura, són essencials en el procés d'identificació dels poemes, per al qual el copista i l'il·luminador d'aquest cançoner deixa petges

els quaderns adaptats a la còpia del Còdex de Cambridge.

25 Els cançoners deixen petges, per tant, dels contextos de difusió de l'obra d'un autor i, en el cas de Roís de Corella, hem pogut recuperar-ne dos ben diferents a partir dels seus cançoners monogràfics: d'una banda, personatges amb poder econòmic i probablement social, interessats a recopilar totes les obres corellanes que tingués a l'abast en un únic volum; d'una altra banda, cercles humanistes en els quals Corella degué ser un model de prosa en vulgar. També els cançoners miscel·lanis ens aporten dades ben interessants, perquè en tots els casos es tracta d'antologies fetes a Catalunya, on es es llegia Joan Roís de Corella i, fins i tot, s'imitava la seua literatura, de la qual cosa és bona mostra la Vida de sancta Bàrbara del Jardinet d'orats (Martos 2000).

26 Sols la tenim, per a l'obra profana, gràcies als repertoris d'Hernando Colón, en el cas del Plant de la reyna Hècuba imprés per Joan Luscher a Barcelona el 1498 (Martos 2008b: 8-9 y 2015a: 129-131).

27 «Esto es así porque la tinta roja de ambos, con una capa de mayor grosor, tiene, en realidad, otro tipo de composición, similar a la de los sellos, que no se ve afectada por la corrosión: su principal componente es la cera natural de abeja, de carácter orgánico, a la que se añaden pigmentos que le aportan su característico color rojo, como son el bermellón (sulfato de mercurio) y el minio (óxido de plomo)» (Martos 2016c: 185).

28 Quan hi són, com en el Leànder y Hero, perquè la Tragèdia de Caldesa, per exemple, no en té i els calderons s'usen exclusivament per als poemes. 
Josep Lluís Martos. La poesia en la prosa de Joan Roís de Corella: delimitació i transmissió del corpus

formals molt clares. El que no s'hi delimita, però, és la tornada dels poemes que en tenen: «D’un bell joyel, senyor, tinch inventiva» $i$ «Mare de aquell qui de la creu en l'arbre». En tots dos casos, s'hi fa una tirada de versos sense estrofisme, un tret que afecta no al procés de catalogació, sinó al d'edició crítica, i que, tanmateix, es respecta escrupolosament en la darrera secció, de poemes independents.

La irrupció de la poesia en la prosa sembla que genera, així mateix, una disfunció per al copista del Cançoner de Mayans, que resol de manera diferent. Quan, dins el mateix epígraf, continua el text en prosa després dels versos, el copista, en uns casos, deixa a l'il·luminador l'espai i la indicació de la grafia minúscula que fa de guia per a la caplletra, que és d'arracada, d'una mesura de tres línies, i que es fa amb el mateix pigment roig que el calderó. En altres casos, però, s'oblida de fer-ho i l'il·luminador recorre, com en les poesies, a encapçalar el nou paràgraf amb un calderó. Els poemes d'un vers de Lo jobí de Paris, com després veurem també en l'altre testimoni, es copien a línia tirada, però un lector subratlla, amb tinta més fosca, els quatre poemes decasíllabs, però no ho fa així amb l'octosíllab. Aquest model de marcació, que ajuda a la seua identificació i que evidencia la concepció com a text independent que ja en tenia un lector antic, el retrobem, de fet, en La sepultura de Franci Aguilar.

El Jardinet d'orats funciona copiant seccions i/o quaderns de manera independent i no és gens sistemàtic en les solucions emprades, fins i tot durant el procés de còpia d'una mateixa obra, tot i que sí que hi ha, en cada cas, unes directrius més o menys semblants i, per això, cal que revisem el textos de manera individualitzada. En el Leànder y Hero, la còpia dels poemes alterna des de l'aglutinació del primer d'ells, fins a les línies de respecte anterior i posterior o a la separació interlineal en la resta. En tots els casos hi ha marca de cesura, de la mateixa manera que sempre s'ocupa amb una ratlla ondulada la resta de la línia fins a l'extrem dret de la caixa d'escriptura. Els versos de tots els poemes s'inicien amb majúscula, però amb diferents tècniques: el tercer d'aquests alinea aquestes inicials amb la caixa i amb la mateixa tinta, mentre que la resta són fora de caixa, amb la tinta de les rúbriques, de traç més gros i color més clar. En el cas del segon poema, la primera caplletra $(D)$ és de major grandària i amb un doble traçat, a la manera de les que inicien els epígrafs en prosa. En els tres poemes que tenen fora de caixa la caplletra, adornada amb un doble traçat més subtil, també presenten majúscules en la primera o, en ocasions, en alguna lletra més de l'inici del vers. El poema final del Leànder y Hero, amb l'epitafi dels amants, no es conserva en aquest testimoni, com veure'm després.

Els dos poemes del Josef presenten una clara distribució en la còpia del Jardinet d'orats, amb separació de versos per línea d'escriptura i amb ratlles en blanc de respecte a dalt i a baix. No tenen marca de cesura i sí de final de línia, amb barra vertical i no amb la ratlla ondulada que caracteritzava els poemes del Leànder y Hero. Tots els versos comencen per majúscula, però en el primer cas està dins de la caixa d'escriptura i unida a la grafia següent, mentre que en el segon està fora de caixa i amb distància entre les dues primeres lletres, com ocorria en la prosa mitològica.

SCRIPTA, Revista internacional de literatura i cultura medieval i moderna, núm. 14/desembre 2019/pp. 243- 260 ISSN: 2340-4841 · doi:10.7203/SCRIPTA.14.16368 
Josep Lluís Martos. La poesia en la prosa de Joan Roís de Corella: delimitació i transmissió del corpus

Quant a la Tragèdia de Caldesa del Jardinet d'orats, els dos poemes tenen línies de respecte anterior i posterior, molt amples, especialment, en el segon, com ocorre també amb la caplletra, que en aquest mateix cas és una $C$ molt gran, de vora quatre ratlles, potser influenciada per la $C$ capitular del paràgraf que precedeix aquesta poesia. Tot i que el primer poema també té caplletres fora de caixa i d'una grandària major que en la resta de poemes en prosa d'aquest cançoner, són més petites que la d'aquest poema de resposta de Caldesa.

Finalment, tot i que les composicions d'un vers de Lo jobi de Paris estan a línia tirada, dins de la caixa d'escriptura de la prosa, un lector antic del Jardinet d'orats en marca els tres centrals amb una manícula, que ajuda al seu reconeixement; no ho fa, per tant, amb l'octosíllab i amb el darrer epigrama del mantell de Venus, hipermètric, no crec que per aquesta raó, sinó per la disfunció de trobar-ne dos en aquest cas, a diferència del que ocorre amb les altres deesses. El poema de la Sentència, amb sis versos, tanmateix, és l'únic cas de la poesia en la prosa del Jardinet d'orats en què, amb més d'un vers, se'n fa la còpia a línia tirada, tot i que s'hi marcava la cesura, potser pensant que eren signes de puntuació de la prosa. Després se n'adverteix l'error i s'hi delimita el canvi de línia amb els traços _ $\left.\right|^{-}$, segons aquesta transcripció: ${ }^{29}$

PRENEV lo pom/ mare del gran cupido I que no es tant clar/ lo lumjnos apollo/

- quōt al mig jōr/ scurex adiana | en axi vens/

/ lo reluēt carboncle en claradat/ a totas las altras pedras $\uparrow$ com venceu vos / apallas he a Juno/

El testimoni imprés del Josef, no distingeix de cap manera el primer epitafi, que es presenta com si fos part de la prosa, probablement per tractar-se sols de dos versos. No obstant això, en el segon dels casos es posa en una tipografia major quasi el primer vers complet, que se sagna cap a dins, $i$, les dues síl·labes restants es copien en la línia inferior, alineada amb les quatre següents. Aquestes venen precedides totes per calderó (C) i comencen amb majúscula, amb la disfunció que les tres primeres són, efectivament, versos, mentre que la darrera, per error del componedor, és ja part del text en prosa que els segueix, segons aquest model:

Mort per amor dins lo negre se

pulcre

C Sta lo cos daquella egipciacha

$\mathbb{C}$ Qui per joseph partint se daquetsegle.

C Ab gran dolor abandona lo viure

C Respon joseph ales paraules dela senyora

29 Substituesc aquest model de traços pel calderó informàtic en la transcripció. 
Josep Lluís Martos. La poesia en la prosa de Joan Roís de Corella: delimitació i transmissió del corpus

Aquests són, de manera sinòptica i comparativa, els testimonis de les obres en prosa i els dels poemes incorporats a elles, unes dades que, en principi, haurien de coincidir, però que, com s'hi veu, no és així, la qual cosa evidencia, per tant, unes peculiaritats en la transmissió textual d'aquest corpus:

\begin{tabular}{|c|c|c|c|}
\hline OBRES EN PROSA & $\begin{array}{l}\text { FONTS } \\
\text { PROSA }\end{array}$ & POESIES & $\begin{array}{l}\text { FONTS } \\
\text { POESIA }\end{array}$ \\
\hline \multirow[t]{3}{*}{ Debat } & \multirow[t]{3}{*}{$\mathrm{U}$} & «Beda sou vós, senyor, quant vos contemple» & $\mathrm{U}$ \\
\hline & & «D’un bell joyel, senyor, tinch inventiva» & $\mathrm{UO}^{4}$ \\
\hline & & «Senyor del món, qui passau en saber» & $\mathrm{U}$ \\
\hline Triümpho de les dones & $\mathrm{UX}^{2}$ & «Mare de aquell qui de la creu en l'arbre» & $\mathrm{UX}^{2}$ \\
\hline Lletra consolatòria & $\mathrm{X}^{2}$ & «Los qui amau, preneu aquesta cendra» & $\mathrm{UX}^{2}$ \\
\hline \multirow[t]{2}{*}{ Tragèdia de Caldesa } & \multirow[t]{2}{*}{$\mathrm{UX}^{1}$} & «Mourà's corrent la tremuntana ferma» & $U X^{1}$ \\
\hline & & «Clarament veig que $\cdot n$ la mundana orla» & $\mathrm{UX}^{1}$ \\
\hline \multirow[t]{5}{*}{ Leànder y Hero } & \multirow[t]{5}{*}{$\mathrm{UX}^{1}$} & «Tan gran dolor lo meu cor trist esquinça» & $\mathrm{UX}^{1}$ \\
\hline & & «Del món no·m dolch, que ma vida vull perdre» & $\mathrm{UX}^{1}$ \\
\hline & & «Lo foch que veig encés alt, en la torre» & $\mathrm{UX}^{1}$ \\
\hline & & «Cuyta, cos mort, que l'amor que $t \mathrm{t}$ fa perdre» & $\mathrm{UX}^{1}$ \\
\hline & & «Amor cruel, qui $\cdot$ ls ha units en vida» & $\mathrm{U}$ \\
\hline \multirow[t]{6}{*}{ Lo johi de Paris } & \multirow[t]{6}{*}{$\mathrm{UX}^{1}$} & «Sia donat a la més bella» & $\mathrm{UX}^{1}$ \\
\hline & & «Obriu los ulls als dans que seguir poden» & $\mathrm{UX}^{1}$ \\
\hline & & «Dins onestat tots mos desigs se tanquen» & $\mathrm{UX}^{1}$ \\
\hline & & «Lo fruyt d'amor ab gran treball se troba» & $\mathrm{UX}^{1}$ \\
\hline & & «Venç gran amor paraules, erbes hi pedres» & $\mathrm{UX}^{1}$ \\
\hline & & «Preniu lo pom, mare del gran Cupido» & $\mathrm{UX}^{1}$ \\
\hline \multirow[t]{2}{*}{ Josef } & \multirow[t]{2}{*}{$\mathrm{UX}^{1} \mathrm{a}$} & «Morta de part, davall la pedra marbre» & $\mathrm{UX}^{1} \mathrm{a}$ \\
\hline & & «Mort per amor, dins lo negre sepulcre» & $\mathrm{UX}^{1} \mathrm{a}$ \\
\hline Magdalena & $\mathrm{U}$ & «Fflor d'onestat, senyora devota» & $\mathrm{U}$ \\
\hline
\end{tabular}

He marcat amb cursiva el testimoni $U$ del primer poema de la Tragèdia de Caldesa, perquè s'ha arrancat un tros de paper de la part superior del f. 39 d'aquest cançoner, ${ }^{30}$ de manera que es perden

30 Per un mal ús i no de manera voluntària, que puguem atribuir a la censura.

SCRIPTA, Revista internacional de literatura i cultura medieval i moderna, núm. 14/desembre 2019/pp. 243- 260 
Josep Lluís Martos. La poesia en la prosa de Joan Roís de Corella: delimitació i transmissió del corpus

dos fragments de l'obra, el corresponent a les dues planes del full. Una de les mutilacions (f. 39v) afecta a dos versos - als segons hemistiquis, en realitat- del primer poema de la Tragèdia (vv. 22-23), per als quals, per tant, sols comptem amb un testimoni, el Jardinet d'orats, marcat amb un fort vernís dialectal (Martos 2001a: 71-87). D'aquesta manera, es traeix el model lingüístic valencià en alguna de les lliçons -«en lo món no y romangue (v. 22)»-, fet poc freqüent en l'edició de l'obra corellana, ben conservada en testimonis occidentals.

En conclusió, de l'anàlisi de les dades del quadre anterior, se'n deriven tres disfuncions entre els testimonis de les obres en prosa i els dels poemes inserits en elles, que s'expliquen de la següent manera:

a) Tot i que la prosa mitològica de Leànder y Hero es conserva en dos testimonis, el darrer dels poemes ho fa exclusivament en el Cançoner de Mayans, perquè els folis amb numeració antiga 141, 142 i 143 del Jardinet d'orats, just al darrere de la Istòria de Leànder y Hero, són eliminats $i$ això té unes conseqüències importants en la transmissió del text, perquè es perd el final d'aquesta prosa mitològica, ${ }^{31}$ que devia trobar-se a l'inici del f. $141^{\text {r: }}$ l'epitafi i el darrer paràgraf, per als qual, per tant, sols comptem amb un testimoni, tot i que aquest poema funerari de tres versos també s'aprofita en el Tirant lo Blanc (cap. 485) per als dos protagonistes, amb algunes variants. ${ }^{32}$

b) La Lletra Consolatòria es conserva exclusivament en el Còdex de Cambridge, però el poema que remata la prosa té doble testimoni i, així, també el trobem en el Cançoner de Mayans, però com a primera cobla del poema independent que coneixem des de Miquel i Planas com a Desengany. En les darreres paraules en prosa de la Lletra consolatòria, que anuncien aquests versos, Corella ens diu: «E, perquè més scriure seria de letra passar los llímits, comanant-me a vós, abandone la ploma, scrivint per peu una mal rimada cobla que ha temps tinch feta en los infortunis de ma benvolença» (Martos 2005b: 25). Aquesta cobla mal rimada ('en versos estramps') no sols era anterior al text en prosa, ${ }^{33}$ sinó, molt probablement, també a l'estadi que conservem del poema Desengany.

c) Finalment, sols coneixem el Debat amb elpríncep de Viana pel Cançoner de Mayansi, malgrat això, el segon dels tres poemes que hi incorpora Roís de Corella ${ }^{34}$ compta amb dos testimonis.

31 És això i no cap altra hipòtesi, com ara considerar-lo com a versió, perquè el text del f. $140^{\vee}$ acaba anunciant l'epitafi i no hi ha, a més, cap signe material de conclusió de l'obra.

32 Si es poden dir així, perquè, sensu stricto, no es tracta d'un segon testimoni textual: «Amor cruel, qui·ls ha units en vida / y ab greu dolor lo viure·ls ha fet perdre, / aprés la mort los tanque·n lo sepulcre». Per a la seua rendibilitat ecdòtica, en qualsevol cas, vegeu Martos 2001a: 360 i 2016a: 42.

33 Vegeu, per a aquesta qüestió, Martos 2005a: 1162-1163.

34 Perquè també hi ha uns versos de Carles de Viana, que semblent haver format part d'una composició seua remesa a Joan Poeta, segons en diu el príncep mateix. 
Josep Lluís Martos. La poesia en la prosa de Joan Roís de Corella: delimitació i transmissió del corpus

Això és perquè també es conserva en el Cançoner de París $\left(O^{4}\right),{ }^{35}$ tot i que en aquest cas com a poema independent, ${ }^{36}$ a la manera dels elogis intercanviats amb Carles de Viana, també transmesos per aquest manuscrit (ff. $176^{\mathrm{rv}}$ ) ${ }^{37}$ després dels quals, de fet, es copia aquesta composició incorporada a la prosa (ff. $\left.176^{\mathrm{v}}-177^{\mathrm{r}}\right){ }^{38} \mathrm{Si}$ bé els poetes, el tema i l'estructura mètrica relacionen tots tres poemes, les rúbriques d'aquest cançoner ${ }^{39}$-si més no- semblen descartar que «D'un bell joyell, sennor, tinch inventiva» siga una contraresposta als elogis anteriors, ${ }^{40}$ la qual cosa no invalida que fos un poema previ incorporat a la prosa, com ocorria amb els versos de Carles de Viana, que formaven part d'una composició adreçada prèviament a Joan Poeta. Així ho reconeixia el príncep en el text, de fet, de la mateixa manera que Corella ho va explicitar quant al poema de la Lletra consolatòria.

En parlar del procés de formació del Cançoner de París, vaig avançar en nota a peu el que, en realitat, és una de les principals conclusions d'aquest treball, de la qual estic plenament convençut -ho diu Corella, en realitat- i que difumina els límits entre la seua poesia independent i els versos en la prosa: «Este cancionero podría ser, por lo tanto, un argumento más para mi hipótesis sobre la incorporación de poemas previos a las prosas corellanas -como debió de ocurrir con el primero de la Tragèdia de Caldesa, con la conclusión de la Lletra consolatòria y, probablemente, con alguno del Leànder y Hero-, combinada con la redacción de textos nuevos ad hoa» (Martos 2015b: 140, nota 93).

35 Segons les sigles de Massó i Torrents (1913-1914 i 1932), però la tradició textual de Ausiàs March, establerta per Pagès (1912-1914) l'identifica com a testimoni $B$.

36 Com ja havia advertit Miquel i Planas: « Dun bell joyell - senyor, tinch inventiva...» Són els versos ab que termina una de les cartes de Mossèn Corella al Príncep de Viana (Debat epistolar, 251-262), considerats aquí com a obra independent» (1913: XXXIII).

37 «Que no son unas preguntas y respuestas, como se ha insinuado de manera insistente, probablemente al existir un debate en prosa y, quizás, derivado de las rúbricas Corella al senyor príncep y Resposta del senyor princep o de la descripción que Morel-Fatio, dependiendo de ellas, hizo del segundo texto -«Réponse à la pièce de Corella, intitulée: 'Ffenix del mon'» (1892: 364). Una respuesta, sin embargo, no implica una demanda, sino que puede tratarse de la reacción ante un poema de elogio, como es el caso. Debió de ser Massó i Torrents quien introdujo el error en la tradición crítica, al referirse a ellas como «debat poètic entre Joan Roig de Corella i el príncep de Viana» (1932: 19), sin distinguir, ni siquiera, entre los tres poemas recogidos» (Martos 2015b: 139-140).

$38 \mathrm{Al}$ davant de tots tres poemes es copia el maldit destinat $A$ Caldesa (f. $176^{\mathrm{r}}$ ), que obri una breu secció de quatre composicions de Roís de Corella en aquest cançoner dedicat a l'obra d'Ausiàs March.

39 Les dues primeres composicions estan, com en el Cançoner de Mayans, clarament relacionades per les rúbriques, mentre que la tercera es limita a indicar Corella al príncep, sense al·lusió directa als poemes anteriors.

40 Com pensava Archer: «Un poema de Corella al príncep de Viana, «Ffènix del món de qui·l saber stilla», la Resposta del príncep (una cobla i una tornada) i una contraresposta de Corella» (1997: 13). 
Josep Lluís Martos. La poesia en la prosa de Joan Roís de Corella: delimitació i transmissió del corpus

\section{Bibliografia}

Aguiló i Fuster, Marià (1923) Catálogo de obras en lengua catalana impresas desde 1474 hasta 1860, Madrid, Sucesores de Rivadeneyra.

Almiñana Vallés, Josep (ed.) (1984-1985) Obres de Joan Roiç de Corella, València, Del Cénia al Segura, 2 vol.

Alvar, Carlos (2019) «Inserciones líricas en textos narrtivos: los orígenes», dins Josep Lluís Martos i Natalia A. Mangas (eds.), Pragmática y metodologias para el estudio de la poesía medieval, Alacant, Universitat d’Alacant («Colección Cancionero, Romancero e Imprenta», 2), pp. 381-400.

Archer, Robert (ed.) (1997) Ausiàs March, Obra completa. Apèndix, Barcelona, Barcanova.

Badia, Lola (1988) ««En les baixes antenes de vulgar poesia»: Corella, els mites i l'amon», dins De

Bernat Metge a Joan Roís de Corella. Estudis sobre la cultura literària de la tardor medieval catalana, Barcelona, Quaderns Crema («Assaig», 8), pp. 145-180.

Bohigas, Pere (1985) «Repertori de manuscrits catalans. Missió a Anglaterra», dins Sobre manuscrits $i$ biblioteques, Barcelona, Curial Edicions Catalanes/Publicacions de l'Abadia de Montserrat, pp. 20-70 [1a ed.: Estudis Universitaris Catalans, 12 (1927)].

Carbonell, Jordi (1973) «Estudi preliminan» a Joan Roís de Corella, Obres completes, 1. Obra profana, València, Albatros Edicions, pp. 7-38.

Cátedra, Pedro M. (1993) «El entramado de la narratividad: tradiciones líricas en textos narrativos españoles de los siglos XIII y XIX», Journal of Hispanic Research, 2, pp. 323-354.

Deyermond, Alan D. (1975) «Lyric Traditions in Non-Lyrical Genres», dins Studies in Honor of Lloyd Kasten, Madison, HSMS, pp. 39-52.

Ferrando Francés, Antoni (1981) «Unes poesies valencianes del 1543 sobre el tema de la Malmonjada», Revista Valenciana de Filologia, 7/4, pp. 391-402.

González Cuenca, Joaquín (ed.) (2004) Hernando del Castillo, Cancionero general, Madrid, Editorial Castalia, 5 vol.

[GW] Gesamtkatalog der Wiegendrucke, Leipzig, K. V. Hiersemann, 1925-actualidad [http://www. gesamtkatalogderwiegendrucke.de] [data de consulta: 24 d'octubre de 2019].

Haebler, Konrad (1903-1917) Bibliografía ibérica del siglo XV, 2 vols., La Haia, Martinus Nijhoff.

[ISTC] Incunabula Short Title Catalogue, Londres, British Library [http://www.bl.uk/catalogues/istc] [data de consulta: 24 d'octubre de 2019].

Martín Abad, Julián (2001) Post-incunables ibéricos, Madrid, Ollero y Ramos [1ª adenda: 2007. $2^{\mathrm{a}}$ adenda: 2016].

Martos, Josep Lluís (1999a) «El Cançoner de Maians (BUV MS 728): un cançoner d'autor de Joan Roís de Corella», dns Miscel·lània Arthur Terry, 3, Barcelona, Publicacions de l'Abadia de Montserrat, pp. 93-113 («Estudis de Llengua i Literatura Catalanes», 39).

—_. (1999b) «El Còdex de Cambridge del Trinity College, R. 14. $17\left(X^{2}\right)$ : descripció i estudi», dins Santiago Fortuño i Tomàs Martínez (eds.), Actes del VII Congrés Internacional de l'Associació Hispànica de Literatura Medieval (Castelló de la Plana, 22-26 de setembre de 1997), 2, Castelló de la Plana, Universitat Jaume I, pp. 443-460. 
Josep Lluís Martos. La poesia en la prosa de Joan Roís de Corella: delimitació i transmissió del corpus

Martos, Josep Lluís (2000) «La Vida de Sancta Bàrbara del Jardinet d'orats: Joan Roís de Corella o la recepció de la seua obra», dins Margarita Freixas i Silvia Iriso (eds.), Actas del VIII Congreso Internacional de la Asociación Hispánica de Literatura Medieval (Santander, 22-26 de septiembre de 1999), Santander, Consejería de Cultura del Gobierno de Cantabria-Año Jubilar Lebaniego-Asociación Hispánica de Literatura Medieval, pp. 1269-1287.

- (ed.) (2001 a) Les proses mitològiques de Joan Roís de Corella: edició crítica, Alacant/Barcelona, Institut Interuniversitari de Filologia Valenciana/Publicacions de l'Abadia de Montserrat («Biblioteca Sanchis Guarner», 55).

—. (2001b) Fonts i cronologia de les proses mitològiques de Joan Roís de Corella, Alacant, Universitat d'Alacant («Biblioteca de Filologia Catalana», 10).

— - (2001c) «La génesis de un cancionero catalán de autor: Joan Roís de Corella y el Cançoner de Maians», dins Patrizia Botta, Carmen Parrilla i Ignacio Pérez Pascual (eds.), Canzonieri iberici, A Coruña, Editorial Toxosoutos/Università di Padova/Universidade da Coruña, pp. 313-328.

- _. (2005a) «AAmor és tal que, si us obre la porta, / tart s'esdevé que pels altres la tanque»: una reinterpretació de la Tragèdia de Caldesa», dins Rafael Alemany, Josep Lluís Martos i Josep Miquel Manzanaro (eds.), Actes del X Congrés Internacional de l'Associació Hispannica de Literatura Medieval, III, Alacant, Institut Interuniversitari de Filologia Valenciana («Symposia Philologica», 12), pp. 1147-1167.

—. (2005b) «La Lletra consolatòria de Joan Roís de Corella: edició crítica», Revista de Literatura Medieval, 17, pp. 9-30.

- - (2005c) «El Còdex de Cambridge, el Cançoner de Maians y el Jardinet d'orats a través de la obra de Roís de Corella», dins Manuel Moreno i Dorothy S. Severin (eds.), Los cancioneros españoles: materiales y métodos, Londres, Queen Mary-University of London, pp. 113-140 («Papers of the Medieval Hispanic Research Seminar», 43).

- - (2008a) «Fechas para la datación del Còdex de Cambridge», Critica del Testo, 11/3, pp. 87-108.

—. (2008b) «La literatura perduda de Joan Roís de Corella: les fonts», Caplletra, 45, pp. 93-112.

—_. (2009) «L'escondit de Joan Roís de Corella», Revista de Poética Medieval, 22, pp. 115-132.

—. (2010) «March en Corella: asimilación, perspectiva e innovación en la Tragèdia de Caldesa», Boletín de la Biblioteca de Menéndez Pelayo, 86, pp. 17-45.

- - (2012a) «La transmisión de las coplas de bien y mal decir: la sección extravagante del Cancionero generali), dins Marta Haro Cortés, Rafael Beltrán, José Luis Canet i Héctor H. Gassó (eds.), Estudios sobre el «Cancionero general» (Valencia, 1511): poesía, manuscrito e imprenta, València, Universitat de València, pp. 285-297.

- (2012b) «Un impreso poético en el cancionero manuscrito EM6: el pliego suelto 99*RN y el Cancionero generah), Letras (Buenos Aires), 65-66, pp. 243-254.

—_. (2013a) «La poesia de Joan Roís de Corella: textos de rematada», dins Ricard Bellveser (ed.), Any Roís de Corella, València, Institució Alfons el Magnànim, pp. 487-507.

- - (ed.) (2013b) «Heterodoxia y parodia en las coplas de bien y mal decir», dins Mercedes Brea, Esther Corral Díaz i Miguel Ángel Pousada Cruz, Parodia y debate metaliterarios en la Edad Media», Alessandria, Edizioni dell’Orso, pp. 99-123 («Medioevo Ispanico», 5). 
Josep Lluís Martos. La poesia en la prosa de Joan Roís de Corella: delimitació i transmissió del corpus

Martos, Josep Lluís (2015a) «La literatura perduda de Joan Roís de Corella: límites, proceso y resultados de un catálogo», en Estudios de literatura medieval en la Península Ibérica, ed. Carlos Alvar, San Millán de la Cogolla, Cilengua, pp. 123-145.

— - (2015b) «De la filología material a los textos y sus variantes: el proceso de copia del cancionero B de Ausiàs March», Cultura Neolatina, 74/1-2, p. 119-142.

—_. (2016a) «La istòria de Leànder y Hero de Joan Roís de Corella: transmissió textual, anàlisi ecdòtica i edició crítica», dins Antonio Cortijo i Josep Lluís Martos (eds.), The Story of Leander and Hero, by Joan Roís de Corella. A Multilingual Edition of a Classic From the Crown of Aragon (1435-1497), Amsterdam/Philadelphia, John Benjamins Publishing Company, pp. 19-94.

(2016b) «La formación del fondo de la Biblioteca Universitaria de Valencia y la literatura catalana medieval», dins Constance Carta, Sarah Finci i Dora Mancheva (eds.), Antes se agotan la mano y la pluma que su bistoria / Magis deficit manus et calamus quan eius bystoria. Homenaje a Carlos Alvar, vol. 1: Edad Media, San Millán de la Cogolla, Cilengua, pp. 235-250.

- - (2016c) «La Suplicació de natura bumana de Joan Roís de Corella: fragmentos recuperados de una obra perdida», Cultura Neolatina, 75/1-2, pp. 165-201.

Massó i Torrents, Jaume (1913-1914) «Bibliografia dels antichs poetes catalans», Anuari de l'Institut d'Estudis Catalans, 5, pp. 2-276.

- (1932) Repertori de l'antiga literatura catalana: la poesia, 1, Barcelona, Editorial Alpha.

Miquel i Planas, Ramon (ed.) (1913) Obres de J. Roiç de Corella, Barcelona, Casa Miquel-Rius.

Norton, Frederick J. (1978) A Descriptive Catalogue of Printing in Spain and Portugal, 1501-1520, Cambridge, University Press.

Pagès, Amadeu (ed.) (1912-1914) Les obres d'Auحias March, Barcelona, Institut d'Estudis Catalans, 2 vol.

Parramon i Blasco, Jordi (1993-1994) «Una cobla equívoca de Pere Torroella», Boletín de la Real Academia de Buenas Letras de Barcelona, 44, pp. 169-172.

Riquer, Martí de, \& Antoni Comas (1964) Història de la literatura catalana, Barcelona, Ariel, 4 vol. [2a ed.: 1984].

Romero Lucas, Diego (2005) Catálogo gráfico descriptivo de la imprenta en Valencia 1473-1530, València, Universitat de València, 3 vol. [tesi doctoral].

Serrano y Morales, José Enrique (1898-1899) Reseña histórica en forma de diccionario de las imprentas que han existido en Valencia desde la introducción del arte tipográfico en España hasta el año 1868 con noticias bio-bibliográficas de los principales impresores, València, Imprenta de F. Doménech.

Simó, Meritxell (1999) La arquitectura del «roman courtois» en verso con inserciones líricas, Berna, Peter Lang.

Torró, Jaume (1992) «El MS. 151 de la Biblioteca Universitària de Barcelona (Jardinet d'orats): descripció i estudi codicològic», Boletín Bibliográfico de la Asociación Hispánica de Literatura Medieval, 6/1, pp. 1-55 [reed. com a apèndix de la introducció a Romeu Llull, Obra completa, Barcelona, Barcino, 1996, pp. 261-295].

Vindel, Francisco (1946) El arte tipográfico en España durante el siglo XV: Valencia, Mallorca y Murcia, Madrid, Ministerio de Asuntos Exteriores/Dirección General de Relaciones Culturales. 
Josep Lluís Martos. La poesia en la prosa de Joan Roís de Corella: delimitació i transmissió del corpus

Whinnom, Keith (1981) La poesía amatoria en la época de los Reyes Católicos, Kendal, University of Durham.

SCRIPTA, Revista internacional de literatura i cultura medieval i moderna, núm. 14/desembre 2019/pp. 243- 260 ISSN: 2340-4841 · doi:10.7203/SCRIPTA.14.16368 